\title{
The Impacts of Tourism Development at Domboshava National Monument in Zimbabwe
}

\author{
Erisher Woyo ${ }^{1, *}$, Edith Woyo ${ }^{2}$ \\ ${ }^{1}$ Faculty of Strategic Management and Business Administration, International University of \\ Management, Windhoek, Namibia \\ ${ }^{2}$ School of Hospitality and Tourism, Harare Polytechnic, Harare, Zimbabwe
}

\begin{abstract}
Tourism development is regarded as an important means to benefit local communities. The success of tourism in developed countries has inspired Zimbabwe to give recognition to the industry as the main driver in national economic development. This study examines the impacts of tourism development in Zimbabwe using Domboshava National Monument as an exemplar. Fifty questionnaires were distributed to local stakeholders that include monument sites managers, tour guides, tourism developers and community leaders. Descriptive statistics were used to determine the impacts of tourism development. Two key issues were identified in this study and discussed, that is, the benefits of tourism development and the costs of tourism development. Results show that, despite the limitation and development issues at Domboshava National Monument, the positive impacts of tourism development at Domboshava National Monument outweigh the costs accrued by the local community.
\end{abstract}

Keywords: Tourism development, impacts, local community, Domboshava National Monument, Zimbabwe

\section{INTRODUCTION}

The tourism industry is believed to have developed quicker over the last three decades due to advances in information and communication technologies, increase in purchasing power and developments in the global economy (Pestana, Laurent, Nicolas, Elisabeth, Bernardin, \& Assaf, 2011). The economic dimension of this industry is real and it has been considered to be the major foreign currency earners (Future Brands, 2006) and literature chronicling the economic impact of tourism on the growth of economies and local destinations is widely confirmed (Song, Dwyer, Li \& Cao, 2012; Tugcu, 2014; Webster \& Ivanov, 2014), resulting in a growing competition among tourism destinations (Dwyer, Edwards, Mistilis, Roman, \&Scott 2009; Molina, Frías-Jamilena, \& Castaneda-García, 2013; du Plessis, Saayman, and van der Merwe, 2015). The tourism industry is believed to be generating daily revenue of over US\$2 billion (Balakrishnan, 2009) and is predicted to grow by an average of $4.9 \%$ over the next five years (UNWTO, 2015). A record one billion international tourists crossed international boundaries in 2012 while five to six billion are estimated to have travelled within their own countries (UNWTO, 2012, 2015). The same source claims that tourism generate $9 \%$ of the world's GDP; 1 out of every 12 jobs in the world is a tourism related job; it generated US\$ 1.2 trillion and signifies $6 \%$ of the world's trade for 2012. Thus, there is no doubt that, the tourism industry remains the fastest growing service sector in the global economy and hence more research is required on how tourism development tends to impact local economies (Woyo, 2013).

Tourism was among the fastest growing sectors of the Zimbabwean economy contributing significantly to the country's Gross Domestic Product (GDP) during the period 1980 to 1998 (Woyo, 2013). Tourism industry in Zimbabwe has got the potential for growth and the industry currently employs approximately 300000 people directly and indirectly (ZTA, 2011). The government of Zimbabwe through its Short Term Emergency Recovery Programme (STERP), identified as an economic recovery platform with tourism being one of the key economic drivers with potential to contribute towards the country's turn around (STERP, 2009). The inclusive government that was birthed in 2009 has also brought about confidence in destination Zimbabwe. Figure 1 below shows the potential of Zimbabwean tourism industry in terms of arrivals: 


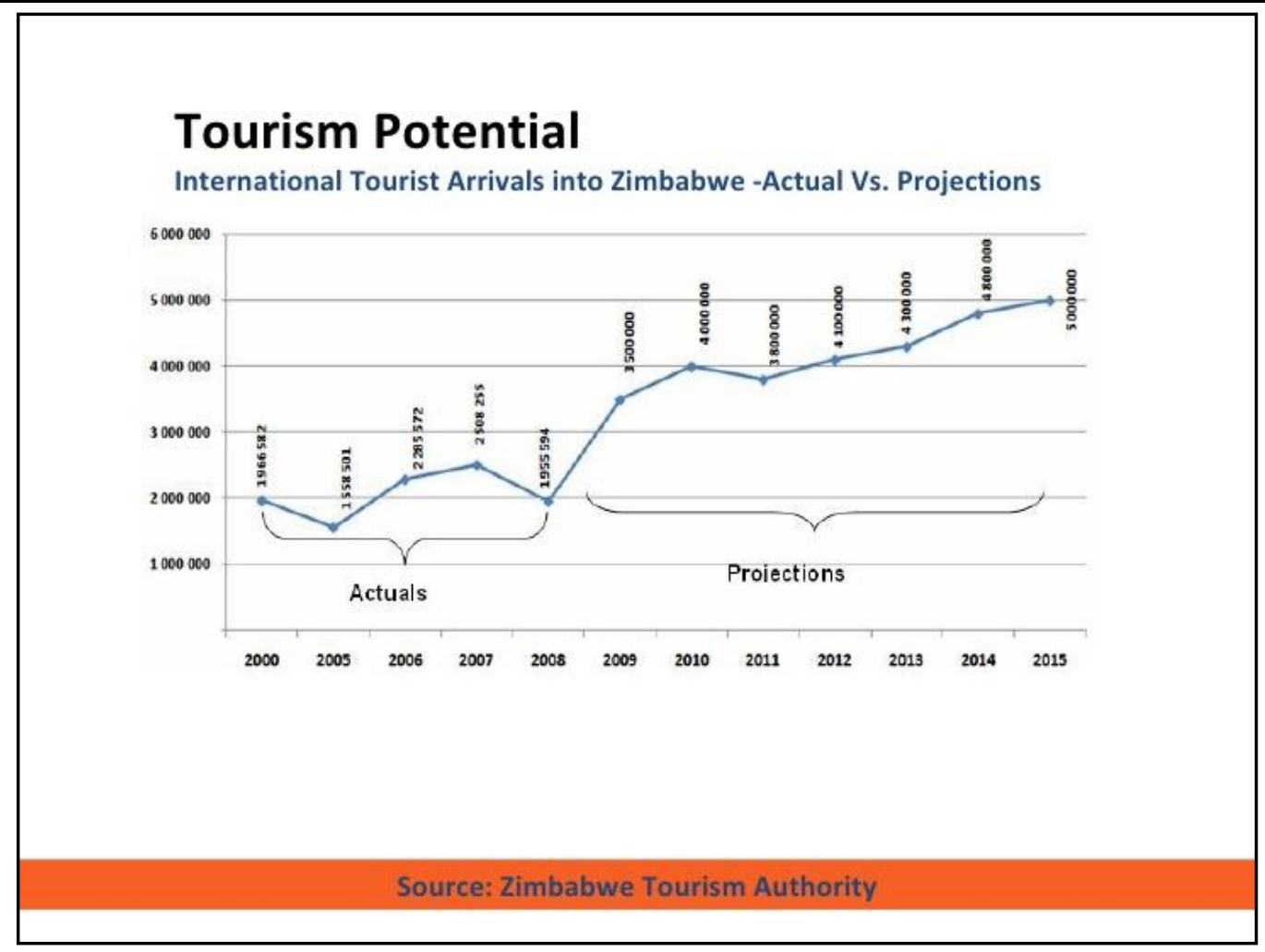

Figure1. Tourism potential in Zimbabwe

Source: ZTA (2013)

Tourism as a means of economic development is less damaging to the environment as compared to extractive industries (Slabbert, 2013). The sustainability debate among researchers is really becoming concerned with grassroots tourism development in terms of participatory planning and the spread of economic benefits between more sectors of the society from which tourism draws its business. Thus, as a response to the negative impacts that have been created by traditions of mass tourism and undifferentiated marketing, tourism industry practitioners and researchers have begun to advocate for the development of tourism that is more sustainable (Slabbert, 2013). Researchers within the broader tourism domain have identified numerous impacts due to tourism development. However, unfortunately, not all the identified impacts are relevant to every community, given that some communities depends on natural resources like wildlife while others favour tourism development with spatial patterns (Slabbert, 2013). Tourism development needs proper planning and management such that natural and cultural environments are not depleted but preserved for posterity (Wall \& Mathieson, 1996). In addition, local community's support is argued to be essential for ensuring long term success of the tourism development process and this is particularly important for cultural heritage sites like Domboshava National Monument. It is practically impossible to sustain tourism business when there is no support from the local community (Aremu, 2001). The research objective of this paper was to provide a context-specific description, analysis and explication of the impacts of tourism development at Domboshava National Monument in Zimbabwe.

\section{LITERATURE REVIEW}

Research regarding the impacts of tourism on communities has been dealt with widely over the last decade (Slabbert, 2013; Lee, 2013). According to the literature, no current study has directly measured the impacts of tourism on local communities in Zimbabwe. Indicators are defined as measurable and manageable variables that tend to characterise quality of a variable of interest (Manning, 1999). Thus, put in the tourism context, tourism development is measured through indicators such as the number of jobs created, foreign currency earned and tourism investments (Song, Dwyer, Li \& Cao, 2012; Tugcu, 2014; Webster \& Ivanov, 2014;Pestana, et al., 2011; Viviers, 2009; Viviers \& Slabbert, 2012). Other indicators of tourism development are increased destination income (Viviers, 2009; Viviers \& Slabbert, 2012). Other useful indicators for tourism development are increased destination income; improvement in the availability of basic services such as health, education and cultural opportunities, as well as reduction in the levels of inequality (Viviers \& 
Slabbert, 2012). However, it is important to note that, tourism impacts have only being measured more frequently focussing on the positive aspects of the economic indicators and a gap exists in terms of the negative economic impacts that tourism development might bring to the residents of the tourist destination.

The issue of how traditional cultures either in whole or in part may be mobilised for economic and social development processes, without damaging the authenticity of culture itself continues to be a major concern when it comes to tourism development. The tourism industry is increasingly seen as a key vehicle that is able to revive and unify local community residents (Fennel, 2003). Research has shown that, at community level, tourism is able to offer direct and indirect opportunities like employment, income, regional and local development (Aref, 2010; Coccossis, 2004), hence the need to monitor tourism development continuously (Godfrey \& Clarke, 2000; Slabbert, 2013). It may be noted that, tourism development may however, bring many and complex results, which therefore calls for proper planning.

Though tourism development cannot be considered an outright economic panacea to problems devilling societies, it is best suited as a supplement for local community for the purposes of achieving development (Godfrey \& Clarke, 2000). Tourism development is belived to be playing a major role in facilitating community development through such issues like business mentoring and educational opportunities and these all contribute towards local communities as well as improving the community's economic level (Brunt \& Courtney, 1999; Goeldner \& Ritchie, 2003; Viviers \& Slabbert, 2012). Local communities turned to tourism development to provide economic, social, cultural and overall community development (Flora, Green, Gale, Schmidt, \& Flora, 1992; Allen, Hafer, Long \& Perdue, 1993; Cook, Yale \& Marqua, 2006; Cooper, Fletcher, Fyall, Gilbert \& Wanhill, 2008). There is paucity of academic research especially when it comes to context specific studies on the impacts of tourism development in Zimbabwe in particular and this ought to constitute an important area of inquiry in tourism studies.

\section{IMPACTS OF TOURISM DEVELOPMENT}

Research into economic and environmental impacts of tourism development has been quite convincing (Song, Dwyer, Li \& Cao, 2012; Tugcu, 2014; Webster \& Ivanov, 2014; Viviers \& Slabbert, 2012; Getz, 2007; Smith, 2006; Andereck, Valentine, Knopf \& Vogt, 2005; Fredline, Jago, \& Deery, 2003; Wall \& Mathieson, 1996). The economic impacts of tourism have been defined as the flow of money through the economy of a host community (Fredline et al., 2003). It is crucial to note that, positive economic impacts have received so much academic attention than the negative economic impacts of tourism development towards host communities, thus, this study will contribute towards this gap by bringing new insights on the negative economic impacts of tourism development, though in a context specific study. Recently, social impacts of tourism have been budding as an area of academic research in recent years (Slabbert, 2013; Viviers \& Slabbert, 2012; Andereck et al., 2005; Fredline et al., 2003; Finsterbusch, 1995; Doxey, 1975; Butler, 1975).

Tourism is a global activity that intertwines economic, environmental, social and cultural elements and the development of tourism usually occurs at national, regional and local levels (Timur, 2003). Within each development level, tourism brings a wide range of economic, environmental and sociocultural benefits to residents such as income generation, job creation, standards of living rise, funds for the community, environmental preservation and the involvement of local residents in management and decision making (Slabbert, 2013; Viviers \& Slabbert, 2012; Andereck et al., 2005; Fredline et al., 2004; Smith, 2001; Wall \& Mathieson, 1996; 2006). On the other hand, tourism development has been proved to be detrimental and tends to threaten both built and natural environments; degrades social fabric systems and culture, infrastructure damage, crime, conflict and fear of foreigners (Choi \& Sirakaya, 2006; Strasdas, 2005; Suansri, 2004). However, it is acknowledged in literature that positive and negative impacts of tourism development are inevitable at whatever level, thus successful tourism development must maximise the positive impacts and minimise the negative impacts of the destinations' environmental, economic, social and cultural resources (Lane, 1994).

Extant literature in context specific studies in Zimbabwe has been limited. Zimbabwe, through NMMZ invests a lot of money in providing public infrastructure and facilities to boost the tourism business at Domboshava National Monument. Despite this, no systematic studies have been 
conducted to relate tourism investments and impacts towards the local economy and socio-culture. Thus, the main focus of the study therefore is to explore and identify economic, environmental and socio-cultural impacts of tourism development within the context of Domboshava National Monument.

\section{MATERIALS AND METHODS: STUDY CONTEXT AND DESIGN}

\subsection{The Brief Description of the Monument}

Domboshava National Monument is located $35 \mathrm{~km}$ from Harare, the capital city of Zimbabwe. Domboshava National Monument was declared a National Monument in 1936 (Pwiti \& Mvenge, 1996) and it is under the management of the National Museums and Monuments of Zimbabwe (NMMZ). The Monument house rock paintings and the rock paintings are found in a rockshelter on the eastern base of an extensive and imposing granite hill as shown in Figure 2 below. The hill, located in the Chinamhora Communal Lands, commands a magnificent view of the surrounding country. Major attractions include an Interpretive Centre or Site Museum, beautiful rock art panels, geological formations and a natural scenic environment such as abundant wooded vegetation, peaceful flowing stream, pools and walking trails.
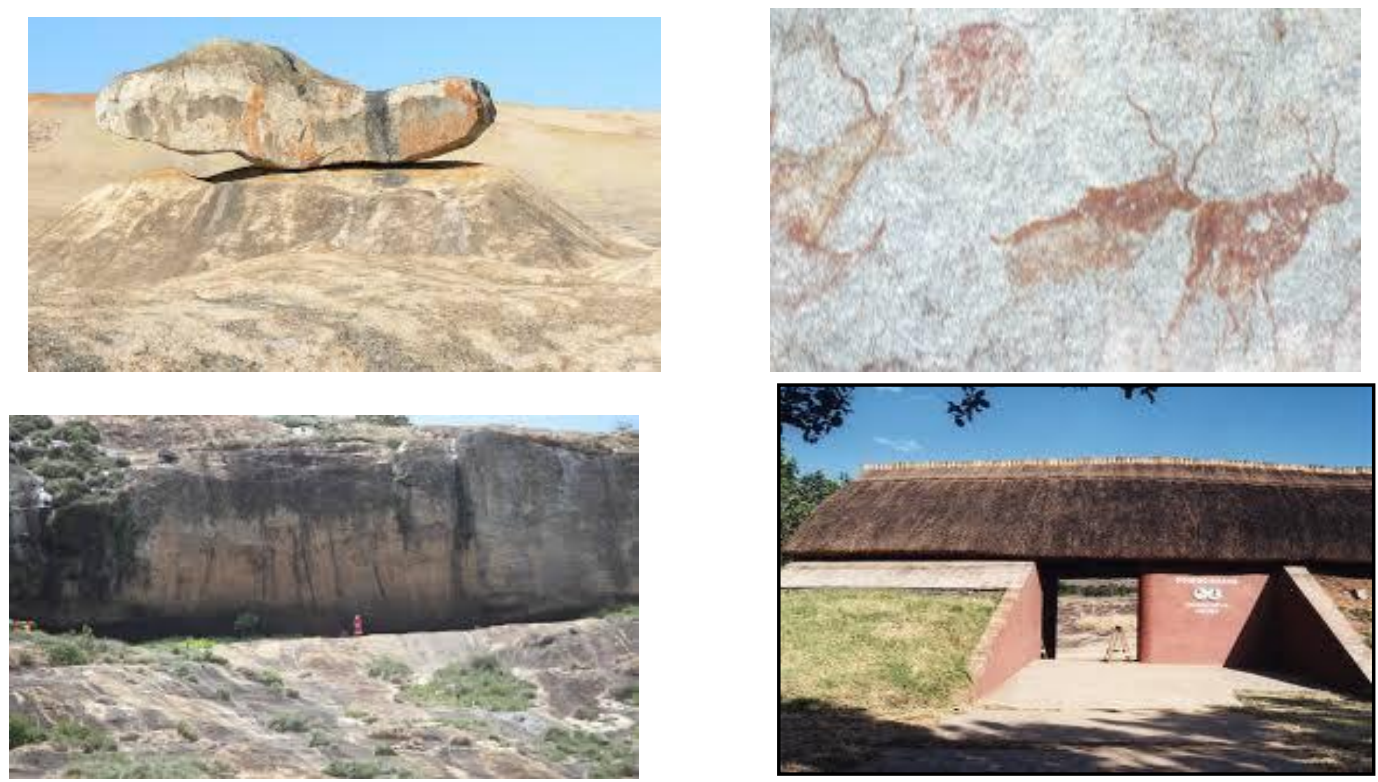

Figure2. Domboshava National Monument

Source: Survey Data

\subsection{Study Design and Focus}

This study seeks to examine context-specific impacts of tourism development at micro level using Domboshava National Monument in Zimbabwe as an exemplar for the period 2010 to 2013. The study followed a case study. A case study approach was adopted in this paper because it entails decisions about the possibility of what to study rather than a methodological choice (Stake, 2005). The tourism operations of the National Museums and Monuments of Zimbabwe is divided into five regions as indicated in Figure 3 and Domboshava National Monument falls into the Northern region.

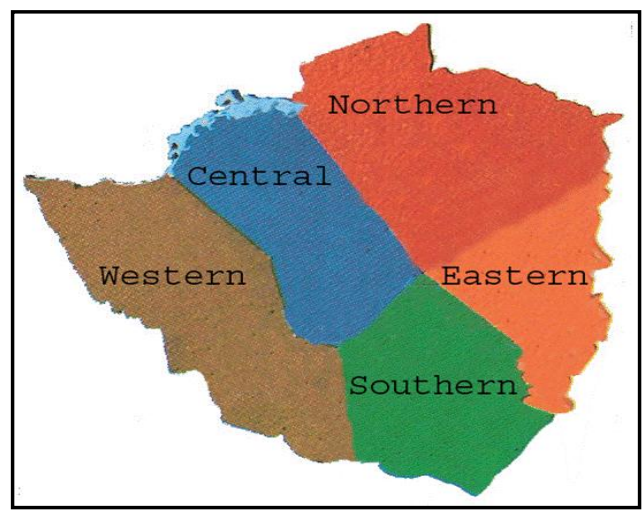

Figure3. Delimitation of $N M M Z$ 


\subsection{The Questionnaire}

Data was gathered by targeting site managers at the monument, tourism developers and local community leaders by means of a structured questionnaire. The questionnaire was divided into two parts. The first segment of the questionnaire captured the demographic details of the respondents and the second segment asked about the impacts of tourism development at Domboshava National Monument.

\subsection{Sampling Method}

Convenience and expert purposive sampling approaches were used to collect data from 50 key informants drawn from surrounding residents and local leaders of the Chinamhora Community where Domboshava National Monument is found, site managers at Domboshava National Monument and tourism developers at the site. Participants were asked about the impacts of tourism development and other aspects of community management including participation, conflict of interest in managing the national monument.

\subsection{Data Analysis}

The purpose of data analysis is to interpret and draw conclusions from the data collected. Data were analysed in terms of the objectives of the study. The data obtained from this study was entered into Portable IBM Statistical Package for Social Scientists version 19.0 for analysis using the descriptive statistics.

\section{FINDINGS}

This section presents the findings of the research study. It begins with the overview of the demographic characteristics of the sample followed by the results on the impacts of tourism development at Domboshava National Monument.

\subsection{Respondents Profile}

The respondents were mostly female (58\%), and were 30 to 65 years old, while the male respondents constituted $42 \%$ of the sample and were 24 to 60 years old. Most respondents were people from Chinamhora community were Domboshava National Monument is $(32.0 \%)$, followed by tour guides (20.0\%); tourism developers $(20.0 \%$; site managers $(10.0 \%)$, and local leaders $(18.0 \%)$. The profile of the respondents is summarised in Table 1 below.

Table1. Demographic Profile of respondents

\begin{tabular}{|l|l|l|}
\hline Variable & $n$ & $\%$ \\
\hline Gender & & \\
\hline Male & 29 & 58.0 \\
\hline Female & 21 & 42.0 \\
\hline Age in years & & \\
\hline $24-30$ & 10 & 20.0 \\
\hline $31-35$ & 15 & 30.0 \\
\hline $36-40$ & 9 & 18.0 \\
\hline $41-50$ & 4 & 8.0 \\
\hline $51-60$ & 5 & 10.0 \\
\hline$\geq 61$ & 7 & 14.0 \\
\hline Marital Status & & \\
\hline Married & 42 & 84.0 \\
\hline Single & 5 & 10.0 \\
\hline Others & 3 & 6.0 \\
\hline Education Level & & \\
\hline Secondary Education & 31 & 62.0 \\
\hline National Certificate & 6 & 12.0 \\
\hline National Diploma & 3 & 6.0 \\
\hline Higher national Diploma & 1 & 2.0 \\
\hline University & 8 & 16.0 \\
\hline Graduate School & 1 & 2.0 \\
\hline Occupation & & \\
\hline Site Managers & 5 & 10.0 \\
\hline Tourism developers & 10 & 20.0 \\
\hline Residents of Chinamhora & 16 & 32.0 \\
\hline Local community leaders & 9 & 18.0 \\
\hline Tour guides & 10 & 20.0 \\
\hline
\end{tabular}


The study used mean as a decision point at 2.5 and any mean value that was 2.5 and above was regarded as agree and below 2.5 was therefore regarded as disagree. Thus, responses of the survey instrument were coded to reflect whether they mentioned positive or negative impacts of tourism development at the monument. A number of positive impacts of tourism development were identified by a number of respondents as shown in Table 2 .

Table2. Impacts of Tourism Development at Domboshava National Monument

\begin{tabular}{|c|c|c|c|c|c|}
\hline \multicolumn{6}{|c|}{ Descriptive Statistics } \\
\hline & $\mathrm{N}$ & Minimum & Maximum & Mean & Decision \\
\hline Improvement of the Environment & 50 & 1 & 2 & 2.52 & Agree \\
\hline Positive Image of the Monument Area & 50 & 1 & 2 & 2.52 & Agree \\
\hline Source of Ecological and Heritage Information & 50 & 1 & 2 & 2.52 & Agree \\
\hline Income Generation & 50 & 1 & 2 & 2.56 & Agree \\
\hline Infrastructural Development & 50 & 1 & 2 & 2.54 & Agree \\
\hline Desecration of Cultural Values & 50 & 1 & 2 & 2.52 & Agree \\
\hline Spirituality of the Monument Compromised & 50 & 1 & 2 & 2.52 & Agree \\
\hline Promotion of Cultural and Heritage Tourism & 50 & 1 & 2 & 2.46 & Disagree \\
\hline Infrastructural Development Pressures & 50 & 1 & 2 & 2.46 & Disagree \\
\hline Conservation of the Cultural Heritage Site & 50 & 1 & 2 & 2.48 & Disagree \\
\hline Employment Creation & 50 & 1 & 2 & 2.50 & Agree \\
\hline New Business Enterprises & 50 & 1 & 2 & 2.42 & Disagree \\
\hline Valid N (listwise) & 50 & & & & \\
\hline
\end{tabular}

Source: Field data

Evidence from table 2 shows that majority of the respondents (90\%) indicated that, tourism development has got more positive impacts on Domboshava National Monument and the surrounding Chinamhora community. In addition to this, there was a general consensus that, tourism development at the monument should continue in the future for the greater good of the future generations of the Chinamhora Community. The reactions of both residents to tourism and the tourism developers at Domboshava National Monument are satisfied with the way tourism has been developing at Domboshava National Monument. Perception of personal impacts and community impacts shows that on average, they are positive at both levels. Thus, it was overall found that tourism development at Domboshava National Monument has got more positive impacts than the negative outcomes of the development process.

The residents of tourism in Chinamhora community view tourism with a more positive side than the negative aspects. Thus, it can be seen as presented in Table 2 that, more positive impacts were identified, while only four negative impacts were singled out by the participants of this study. This finding is quite encouraging when compared with negative impacts of tourism development that took place during the construction of certain tourist hotels in Zimbabwe.

\subsection{Specific Impacts of Tourism Development}

The thrust of this study was to identify context-specific impacts of tourism development at Domboshava National Monument in Zimbabwe. The impacts were categorised under economic, sociocultural and environmental impacts.

\subsection{Perceived Economic Impacts of Tourism Development}

Tourism development at Domboshava National Monument is contributing towards employment creation and job opportunities $(m=2.50)$. These opportunities were identified as both direct and indirect contribution of tourism development at the monument. During the period under study, tourism development has resulted in direct tourism jobs at the Monument that includes tour guides, monument custodians, and security officers, bar personnel, waiters and these human resources were drawn from the surrounding Chinamhora community. It was also found that, tourism development has resulted in increase in central government revenues (mean $=2.56)$ and thus, the Monument was able to develop and improve tourism infrastructure facilities of the area such as roads, electricity, piped water, boreholes and entertainment facilities, restaurants and visitor centres among other things via the multiplier of increased income generated. In addition to this, residents were in agreement that, as tourism revenue was increasing, the revenue of the residents also increased through the multiplier concept as they well able to sell curios and other agricultural products to tourists. Thus, it can be noted that, tourism development at the monument increased opportunities for local business activities, like curio shops, craft industries, and agro markets. 


\subsection{Perceived Social Impacts of Tourism Development}

Tourism development at Domboshava National Monument is helping at increasing the positive image of the area at the time Zimbabwe as a destination is being seen as a "bad boy" $(m=2.52)$. Thus, interest in cultural heritage tourism will continue to be generated at the monument given that the destination enjoys a good image is has been widely accepted in literature that, it influences visitor intention (Prayag, 2010). However, the results show that, social impacts of tourism at Domboshava warrant some careful thought because it has got detrimental effects. While tourism development has been credited for improving destination image of the monument area, social ills in form of conflicts were found out as it was reported that a curio shop was set on fire and its contents went up in smoke and some of the rock paintings were spray paint as a way of stopping tourism development at the site (Pwiti \& Mvenge, 1996) This finding is consistent with the Irridex Irritation Model (Doxey, 1975). Desecration of traditional values $(m=2.52)$ was mentioned as one of the social impacts that were being experienced at Domboshava National Monument. Residents to tourism argued that, due to tourism, there was too much access to the sacred forest and uncontrolled access to the sacred cave, thus compromising the spirituality of the monument $(m=2.52)$.

\subsection{Perceived Environmental Impact of Tourism Development}

The physical appearance of the monument has been enhanced by tourism development taking place at the monument $(m=2.52)$. It was also noted that there was improvement in terms of environmental conservation of the heritage and the surrounding environment of the area around the monument $(m=$ 2.52). However, this study could not establish the claims that were made by Pwiti \& Mvenge (1996) regarding the decline of the available habitat for local wildlife of the area. Negative impacts at Domboshava National monument were cited as infrastructural development pressures and the availability of litter due to many vendors near the monument. Tourism development Domboshava is making more people want to reside close too close to the site or have a business close by, thus contributing to development pressures.

\section{Conclusions}

It is clear that tourism development has certain economic, environmental and social impacts and these can be different depending on specific contexts and communities. Tourism development has impacts on any community that experiences tourism development activities and these impacts differ greatly. This study examined the impacts of tourism development at Domboshava National Monument in Zimbabwe as a way of attributing context specific impacts. The findings of the case study of Domboshava National Monument confirmed that generally, there is a favourable perception and a positive attitude toward the tourism development of the destination under consideration. Many of them expect tourism to grow further and more tourists to arrive to the area. It is obvious with the findings that one major reason behind this changing attitude and perception of tourism is perceived positive impacts of tourism on the local community of Chinamhora. The overall impact of tourism on the local community of Chinamhora was positive and significant according to the findings. Two key issues were identified and discussed: the benefits of tourism development; and costs of tourism development. Analysis found that despite the limitation and development issues, the benefits of tourism development at Domboshava National Monument outweighed the costs accrued thereof

Although it is still too early to know precisely, it seems the goals of sustainable tourism development, namely equity, ecological, and cultural integrity, community participation, integration, balance, harmony, and an increased standard of living among local inhabitants, are being met so far at Domboshava National Monument.

\section{RECOMMENDATIONS}

The following recommendations were drawn from the findings of the research work.

- Sustainability that is actively protecting, and supporting the environment for long-term benefit to all

- Growing tourism in a way that ensures that the benefits from growth are not short lived.

- Conserving Domboshava National Monument's environment and spirituality

- Tourism stakeholders should create awareness programs on the impacts of tourism especially the social impacts of tourism. This will help host communities to protect their traditional values and prevent the erosion of their cultural heritage. 
- Policies and practices that ensure the sustainability of the destination and the social lives of the host communities should be developed at the early stage of tourism development to avert the negative social impacts at the maturation of the industry.

- Participation of local communities in tourism development is essential to maximize the potential benefits of this sector, eliminate poverty and conserve nature - maintain the local culture and social structure of the native community

\section{REFERENCES}

Allen, A., Hafer, A., Long, T., \& Perdue, A. (1993). Rural residents' attitudes toward recreation and tourism development.Journal of Travel Research, 31, 27-35.

Andereck, K.L., Valentine, K.M., Knopf, R.C \& Vogt, C.A. (2005). Residents' perceptions of community tourism impacts.Annals of Tourism research, 32 (4), 1056 - 1076.

Aref, F. (2010). Residents' Attitudes towards Tourism Impacts: A Case Study of Shiraz, Iran. Tourism Analysis, 15(2), 253-261.

Aremu, B. A. (2001). Cultural and Eco-Tourism Development in Nigeria. Ibadan: Hole publications.

Brunt, P. \& Courtney, P. (1999). Host Perception of Socio-Cultural Impacts. Annals of Tourism Research 26 (3): 493-515.

Bushell, R., and Eagles, P. (Eds.). (2007). Tourism and Protected Areas: BenefitsBeyond Boundaries. London CAB International, UK.

Butler, W. (1975).Tourism as an agent of social change.In Tourism as a factor in national and regional development.Occasional paper 4, Department of Geography, Trent University, Peterborough, 85 -90.

Choi, H. C., \& Sirakaya, E. (2006).Sustainability indicators for managing community tourism. Tourism Management, 27(6), 1274-1289.

Coccossis, H. (2004). Sustainable tourism and carrying capacity: U.K: Ashgate Publishing.

Cook, R.A., Yale, L. J. \& Marqua, J. J. (2006). Tourism: The Business of Travel. 3rd Edition. New Jersey: Prentice Hall.

Cooper, C., Fletcher, J., Fyall, A., Gilbert, D. \& Wanhill, S. (2008). Tourism: Principles and Practice. 4th edition. New Jersey: Prentice Hall.

Doxey, G.V. (1975) A causation theory of visitor-resident irritants: Methodology and research inferences. In Travel and Tourism Research Associations, Sixth Annual Conference Proceedings (pp. 195-98). San Diego, September.

Dwyer, L., Edwards, D., Mistilis, N., Roman, C., \& Scott, N. (2009).Destination and enterprise management for a tourism future. Tourism Management, 30(1), 63-74.

Fennell, D. A. (2003).Ecotourism: an introduction (2 ed.): Routledge, UK.

Flora, L., Green, P., Gale, A., Schmidt, E., \& Flora, B. (1992). Self-development: A viable rural development option? Policy Studies Journal, 20, 276-288.

Fredline, L., Jago, L. \& Deery, M. (2003).The development of a generic scale to measure social impacts of events.Events Management, 8(1), 23 -37.

Future Brands (2006). "Country Brand Index, 2006", available at: www.futurebrand.com/ 03showcase/leadership/cbi/pdf/cbi_eng06.pdf

Getz, D. (2007). Event tourism: definition, evolution, and research. Tourism Management, 29 (3), $403-428$.

Godfrey, K., \& Clarke, J. (2000).The tourism development handbook: a practical approach to planning and marketing. London: Continuum.

Goeldner, C.R. \& Ritchie, J.R.B. (2003).Tourism principles, practices and philosophies. $9^{\text {th }}$ Ed. Hoboken, N.J.: Wiley

Lane, B. (1994). Sustainable rural tourism strategies: A tool for development and conservation. Journal of Sustainable Tourism, 2(1-2), 102-111.

Lee, T. H. (2013). Influence analysis of community resident support for sustainable tourism development. Tourism Management, 34, 37-46. 
Manning, R. E. (1999). Studies in outdoor recreation: Search and research for satisfaction $\left(2^{\text {nd }}\right.$ Ed.). Corvallis, OR: Oregon State University Press.

Molina, M.A. R., Frías-Jamilena, D. M., \& Castaneda-García, J. A. (2013).The moderating role of past experience in the formation of a tourist destination's image and in tourists' behavioural intentions.Current Issues in Tourism, 16(2), 107-127.

Pestana, B.C., Laurent, B.,Nicolas, P., Elisabeth, R., Bernardin, S. \& Assaf, A.G. (2011). Performance of French destinations: Tourism perspectives. Tourism Management, 32, $141-146$.

Prayag, G.(2010). Brand image assessment: international visitors' perception of Cape Town. Marketing Intelligence and Planning, 28 (4), $462-486$.

Pwiti, G., and G. Mvenge.(1996). Archaeologists, tourists, and rainmakers: Problems in the management of rock art sites in Zimbabwe, a case study of Domboshava national monument. In Aspects of African archaeology: Papers from the 10th Congress of the Pan-African Association for Prehistory and Related Studies, ed. G. Pwiti and R. Soper, 817-24. Harare: University of Zimbabwe Publications.

Short Term Emergency Recovery Programme (2009).Ministry of Finance, Harare.

Slabbert, E. (2013). Reflections on the social value of tourism for South African communities. Inaugural lecture, Tourism Research in Economic Environs and Society, NorthWest University, Potchefstroom, 1-22.

Smith, S. L. (2001).Measuring the Economic Impact of Visitors to Sport Tournament and Special Events.Annals of Tourism Research 28(3) 829-31.

Song, H., Dwyer, L., Li, G., \& Cao, Z. (2012). Tourism economics research: a review and assessment. Annals of Tourism Research, 39(3), 1653-1682.

Stake, R. (2005).Qualitative case studies.In N.K. Denzin \& Y.S. Lincoln (Eds.).The sage Handbook of qualitative research (3rd ed.). (pp. 443 -466). London: Sage.

Strasdas, W. (2005).Community-based Tourism: Between self-determination and market realities. Paper presented at the Tourism Forum International at the Reisepavillon 2005.

Timur, S.(2003). Sustainable urban tourism: A stakeholder theory perspective. Tourism: An International Interdisciplinary Journal, 51(2), 111-126.

Tugcu, C. T. (2014). Tourism and economic growth nexus revisited: a panel causality analysis for the case of the Mediterranean Region. Tourism Management, 42(3), 207-212.

UNWTO (2012)International tourist arrivals grew by $4 \%$ in 2012 to 1.035 billion http:// mkt. unwto. org/en/barometer. Accessed 25/03/2013.

UNWTO. 2015. Over 1 billion tourists travelled abroad in 2014" Tourism Highlights 2014 Edition, Page 2. http://media.unwto.org/press-release/2015-01-27/over-11-billion-tourists-travelledabroad-2014 (Accessed, 15 March, 2015).

Viviers, P. \& Slabbert, E. (2012).Towards an instrument measuring community perceptions of the impacts of festivals.Journal of Human Ecology, 40(3), 197 -212.

Viviers, P. (2009). Towards a social impact measuring instrument for tourism.PhD thesis. North-West University: Potchefstroom.

Wall, G. and Mathieson, A. (2006). Tourism: Change, Impacts and Opportunities. England: Prentice Hall.

Webster, C., \& Ivanov, S. (2014). Transforming competitiveness into economic benefits: does tourism stimulate economic growth in more competitive destinations? Tourism Management, 40(1), 137140.

Woyo, E. (2013). Qualifications must address the needs of commerce: A case of the Hospitality Discipline

ZTA (2011).Trends and Statistics Report. http:// www. zimbabwetourism. net/index. php/ research/ tourism-trends-statistics/item/501-2011-tourism-trends-and-statistics (Accessed 15 September 2015)

ZTA (2013).Trends and Statistics Report. http:// www. zimbabwetourism. net/index. php/ research/ tourism-trends-statistics/item/454-2013-tourism-trends-and-statistics (Accessed 15 September 2015) 